IOS Press

\title{
Biodegradable mulch films performance for autumn-winter strawberry production
}

\author{
Cláudia Santos Andrade ${ }^{\mathrm{a}}$, Maria da Graça Palha ${ }^{\mathrm{b}, *}$ and Elizabeth Duarte \\ ${ }^{a}$ Casa Prudêncio, Quinta de S. Roque, Almeirim, Portugal \\ ${ }^{\mathrm{b}}$ Instituto Nacional de Investigação Agrária e Veterinária, Quinta do Marquês, Oeiras, Portugal \\ ${ }^{\mathrm{c}}$ Instituto Superior de Agronomia, Tapada da Ajuda, Lisboa, Portugal
}

Submitted 21 April 2014; accepted 4 July 2014

\begin{abstract}
An enormous amount of plastic waste resulting from the agricultural activities is produced every year. Part of this plastic remains in the fields, while the other part is sent to recycling or landfill. The use of biodegradable (BD) mulch films can play a key role towards a sustainable development in agricultural sector because they can be plugged in the soil, after its use, together with the crop residues. The aim of this study was to evaluate the performance of white-on-black biodegradable mulch films in contrast to the conventional polyethylene (PE) mulch film in autumn-winter cycle strawberry production, monitoring the variation on soil warming, lifetime of the films in the field as well as the effects on fruit yield. Soil temperatures showed differences among treatments during summer period under open field conditions and autumn-winter season under tunnel. Although the degradation rate of BD mulch films varied along the crop cycle, they provided adequate bed cover and weed suppression until crop end. Plants had similar monthly crop yield distribution, and percentage of commercial and uncommercial fruits between mulch treatments. From the overall results obtained, biodegradable mulch films may be a promising alternative to PE mulching but there should be economic incentives for growers to implement this sustainable practical as its price at present are not yet competitive.
\end{abstract}

Keywords: Soil mulching, white-on-black films, sustainability, agriculture biodegradable polymers, long cycle crop

\section{Introduction}

From a crop production perspective, plastic mulches can increase yields, extend the growing season, reduce weed pressure, increase fertilizer use efficiency, conserve soil moisture, and increase soil temperature [1]. For these reasons, polyethylene (PE) mulches have been used in agriculture for over half a century [2]. The major limitation of polyethylene mulch involves disposal of mulch material after use due to high molecular weight and hydrophobic properties. Current disposal options as reviewed by Hayes et al. [3] include burning, incineration, recycling, composting and using landfills; each have major economic or environmental disadvantages [4].

Recently, biodegradable mulch films (BD) have been seen as a more sustainable and ecological alternative to polyethylene mulch [5]. Although some commercially available biomulchfilms are compostable, reliable in-soil biodegradation of mulches has not yet been fully understood. One of the main challenges of this biodegradable mulch is to be able to respond to all the functional requirements, during its lifetime, as the conventional ones [5]. At the end of the crop cycle the BD mulches are buried into the soil with the crop residues and are expected to be fully biodegraded within a reasonable time under real field conditions. BD films theoretically can save significant labour and disposal costs through incorporation via soil tillage operations rather than disposal in landfills [6].

\footnotetext{
*Corresponding author: Maria da Graça Palha, Instituto Nacional de Investigação Agrária e Veterinária (INIAV), Quinta do Marques, 2784-505 Oeiras, Portugal. Tel.: +351 214403692; E-mail: graca.palha@iniav.pt.
} 
The replacement of traditional plastics, with renewable and biodegradable polymers has been particularly welcome. Several approved brands of totally or partially biodegradable mulches have already proven reliable in terms of agricultural performance [7] in several crops, including strawberry [5, 8-11].

Strawberry crop production is a very high consumer of agricultural plastics in Southern Europe either for covering the crop (low and high tunnels) or the soil (mulching). Plants are grown in intense annual production systems in raised beds covered with polyethylene film, drip irrigation underneath and high planting density [12]. In Portugal the consumption of PE mulches in strawberry production, is estimated in $138 \mathrm{t}$ per year [13]. In autumn-winter cycles plants are typically grown on raised beds covered with white on black plastic mulches in a long crop cycle (6 to 9 months). This kind of production cycle is unusual being very challenging for farmers by its adding value. Mulch films are used only in one growing season as consequence of their prolonged exposure to climatic agents that lead to a decrease on mechanical properties [14] and due to cultural practices that include soil preparation - and sometimes soil disinfection - in order to achieve good conditions to install the next crop/crop cycle.

Biodegradable mulch (BD) films are so a promising new material providing a more convenient, environmentally friendly alternative for this crop, showing enhanced biodegradability [11] but having as main constrain to the farmer's acceptance the high cost [6]. However, it is important to analyze carefully all the costs associated to the recovery/recycle and disposal of the conventional mulch. In several European countries, there are economic incentives to the use of these new environmentally friendly materials, avoiding the negative impact of the PE mulches residues. In Portugal, these incentives exist but are not selected as a priority by farmers, mainly due to the lack of information about the performance of these new materials.

The aim of this study was to assess the performance of three BD white on black mulches, in comparison with one PE mulch, in order to assess if BD films are viable substitutes to PE in an autumn-winter strawberry crop cycle, reducing the environmental impact. To achieve the main objective were monitored the variation on soil warming, lifetime of the films, crop yield and degradation rate of the exposed and buried BD mulch films.

\section{Material and methods}

\subsection{Experimental field trial}

Field trial was conducted in a commercial strawberry farm (Casa Prudêncio Sociedade Agro-pecuária Lda), located in the central area of Portugal, in the Ribatejo region $\left(39^{\circ} 10^{\prime} \mathrm{N}, 8^{\circ} 39^{\prime} \mathrm{W}, 10 \mathrm{~m}\right.$ above sea), from June 14 th 2010 till January 11th 2011, in a sandy-loam soil.

The experiment was set up in a randomized block design with 4 plots and 4 mulch film treatments in an area of $325.0 \mathrm{~m}^{2}\left(6.5 \mathrm{~m}\right.$ wide $\times 50 \mathrm{~m}$ long). Each plot consisted of one raised bed with $11.55 \mathrm{~m}^{2}(1,1 \mathrm{~m}$ wide and $10.5 \mathrm{~m}$ long) with 66 plants.

The BD mulches were of starch-based raw material supplied by Polivouga enterprise (M1-Biomind) and by Silvex (M2 and M3Mater-Bi); the conventional mulch film was a low-density polyethylene (PE) purchased from Polivouga (M4). The characteristics of the mulch treatments are described in Table 1. All mulches were bicolor: white on upside and black on downside sheet.

Table 1

Characteristics of white-on-black mulch films treatments

\begin{tabular}{lccr}
\hline & M1 & M2 & M3 \\
\hline Raw material & Biomind & Mater-Bi $^{\circledR}$ & Mater-Bi $^{\circledR}$ \\
Thickness $(\mu \mathrm{m})$ & 31 & 20 & 25 \\
Film width $(\mathrm{mm})$ & 1500 & 1400 & 40 \\
Density $\left(\mathrm{g} / \mathrm{cm}^{3}\right)$ & 1.35 & 1.20 & 1400 \\
Elongation at break $(\%)$ & 450 & 335 & 1.20 \\
Tensil strength $(\mathrm{MPa})$ & 18 & 23.6 & 390 \\
\end{tabular}


In June 2010, planting beds were performed with a standard bed maker machine $0.50 \mathrm{~m}$ wide and $0.40 \mathrm{~m}$ high and were covered with white on black PE mulch film of $40 \mu \mathrm{m}$ thickness. Beds were fumigated with $400 \mathrm{~L} \cdot \mathrm{ha}^{-1}$ of metam sodium through drip irrigation system to eliminate soil borne diseases, nematodes, and weeds in the soil. Beds covering remained for one month. After on M1, M2 and M3 plots the PE mulch was replaced with the corresponding biodegradable films treatments by hand.

On July 14th strawberry frigo plants were set in double rows per bed with plant distance $0.30 \mathrm{~m}$ between plants and $0.30 \mathrm{~m}$ between rows, giving a plant density of 6 plants per $\mathrm{m}^{2}$. After plantation, sprinkler irrigation along with drip irrigation was used during 45 days for better plant establishment, followed by drip irrigation.

The crop was conducted in open field during July, August and September and under tunnel from October till December. High multi-tunnels of metal structure were mounted with an opening in each of the tops, oriented in NE-SW direction. The tunnels were covered on September 30th with transparent thermal polyethylene of $200 \mu \mathrm{m}$ thickness. The use of high tunnel during autumn is mainly to protect strawberry from rain and fungal diseases and to enhance fruit appearance [12]. After end of fruit harvesting (December 20th) tunnels were removed from the experiment.

Fertilizers were provided by a drip computerized system and fertigation and pest control were done according to established practice. Phytosanitary treatments for Oidium sp., Botrytis sp., caterpillars, thrips and spider mites were applied.

\subsection{Mulch films performance}

The performance of the mulch films was assessed during three stages of the experiment: stage 1 - open field (from plantation to beginning of harvesting); stage 2 - tunnel (harvesting period); and stage 3 - open field (Table 2). The degradation of the exposed mulch films was evaluated every two weeks by visual observations. The measurements were performed according to a visual scale evaluation 0-9 [15] where 0 was 0-9\% mulch cover and 9 was $90-100 \%$ mulch cover. Degradation of 8 to 9 correspond to mulch film in very good condition, 6 to 8 in good condition, 4 to 6 in satisfactory condition and less than 4 in bad condition.

In stage 3, after harvesting season, tunnels were dismantled and the aerial part of the plants was cut. Before the incorporation of the biodegradable mulch films a final measurement of the mulch films degradation was made by photographs and with the help of AUTOCAD program (2004 version). The images were flattened and the area of uncovered soil bed of each treatment was measured, taking in account the subtraction of plantation holes area.

At the end of the trial, drip irrigation system and the conventional mulch film were removed manually from the experiment. The biodegradable films were tilled together with soil and plant residues by a harrow in order to break up and to bury them. After the conclusion of the study the experimental area was left uncultivated.

\subsection{Meteorological data and soil temperature}

Air temperature, relative humidity, precipitation, and total solar radiation were hourly collected at an automatic weather station (iMETOS, Pessl Instruments). These data were collected during open field and tunnel environment conditions.

In order to determine the effect of the mulch treatments on soil temperature under field conditions, measurements of temperature were recorded at $0.15 \mathrm{~m}$ soil depth, every hour, with Soil Temperature Probe IM 5041D sensor SMT16030 (Pessl Instruments), from August 2nd till end of the crop cycle. The sensors were located underneath the mulch of each plot, in the middle of the bed.

Table 2

Stages of the experimental field trial for mulch film degradation analysis

\begin{tabular}{llll}
\hline Stage & Period & \multicolumn{1}{c}{ Beginning - end } & Environment \\
\hline 1 & 14 July-29 Sept. & Mulching installation - high tunnel collocation & Open-field \\
2 & 30 Sept.-20 Dec. & High tunnel collocation - end of harvesting season & Tunnel \\
3 & 21 Dec.-10 Jan. & End harvesting season - film buried & Open-field \\
\hline
\end{tabular}




\subsection{Plant productivity}

Fruits at commercial ripening stage were harvested from each plot (30 plants) three times a week between September 17th and December 20th. At each harvest, the number and the fresh weight of the fruits were recorded separately for marketable and non-marketable (deformed and diseases) fruits. Total yield, average fruit weight and number per plant were calculated for all treatments.

\subsection{Costs analysis}

A cost analysis per hectare of biodegradable mulch films in comparison to the conventional PE mulch was made based on current prices for 2010, on quantity of plastic used and on incorporation, removal and disposal costs. A comparison of costs was also made applying the Portuguese financial support for the application of BD mulches, which is $31.3 \%$ of product cost.

\subsection{Statistical analysis}

Fruit yield data were subjected to analysis of variance (ANOVA) and a LSD range test $(P<0.05)$ was applied to the significant results, using the program STATISTICA version 6.0 software.

\section{Results and discussion}

\subsection{Soil temperature}

Soil temperature decreased throughout the crop cycle, with mean values higher than air temperature, except at the end of the season (Fig. 1).

Soil temperatures showed some differences between PE and BD materials during summer period under open field conditions and in autumn-winter period under tunnel protection. The values recorded under BD films, especially M2 treatment, were always higher than those under PE mulch (Table 3). This was also related in previous report [16]. Following this period, differences in soil temperature among treatments became practically undetectable.

PE mulch film have lower water vapor permeability than BD mulch films and remains practically constant for longer periods due to its good chemical stability [17]. As consequence, in mulches with same film thickness, it is expected to find higher soil temperatures under PE due to the higher permeability of the biodegradable films to water vapor $[10,11,17]$. In this experiment, the higher film thickness of PE $(40 \mu \mathrm{m})$ resulted in less soil heating. Besides, according to Vox and Schettini [16] mulch films with different thicknesses have different radiometric properties which also affect soil temperature.

Differences in soil temperature among treatments were more evident early in the growing season during summer because plants shaded less the mulches and the crop was conducted in open field environment. In late crop season covering the crop with high tunnel and the higher foliage shading contributed to reduce these differences [18].

\subsection{Mulch films performance}

From July till December, the mulches were exposed to different air temperature, relative humidity, rainfall and water sprinkler irrigation, and solar radiation conditions (Table 4).

The first signs of degradation of the exposed mulch film appeared in stage 1 and were presented by M1 with longitudinal tears on both sides of the beds, four weeks after application. M2 film degradation started later on, followed by M3 that initiated to degrade only in the beginning of stage 2, under tunnel environment (Fig. 2). M2 and M3 films also showed tears especially near the planting holes, with the M3 degradation starting later. The PE mulch film remained intact during this stage and during subsequent phases until the end of the experiment.

At the beginning of stage 2 (tunnel protection) the degradation rate of BD mulch films stabilized. Covering the crop with high tunnels reduced the detrimental effects of high doses of UV radiation on the elongation at break of 

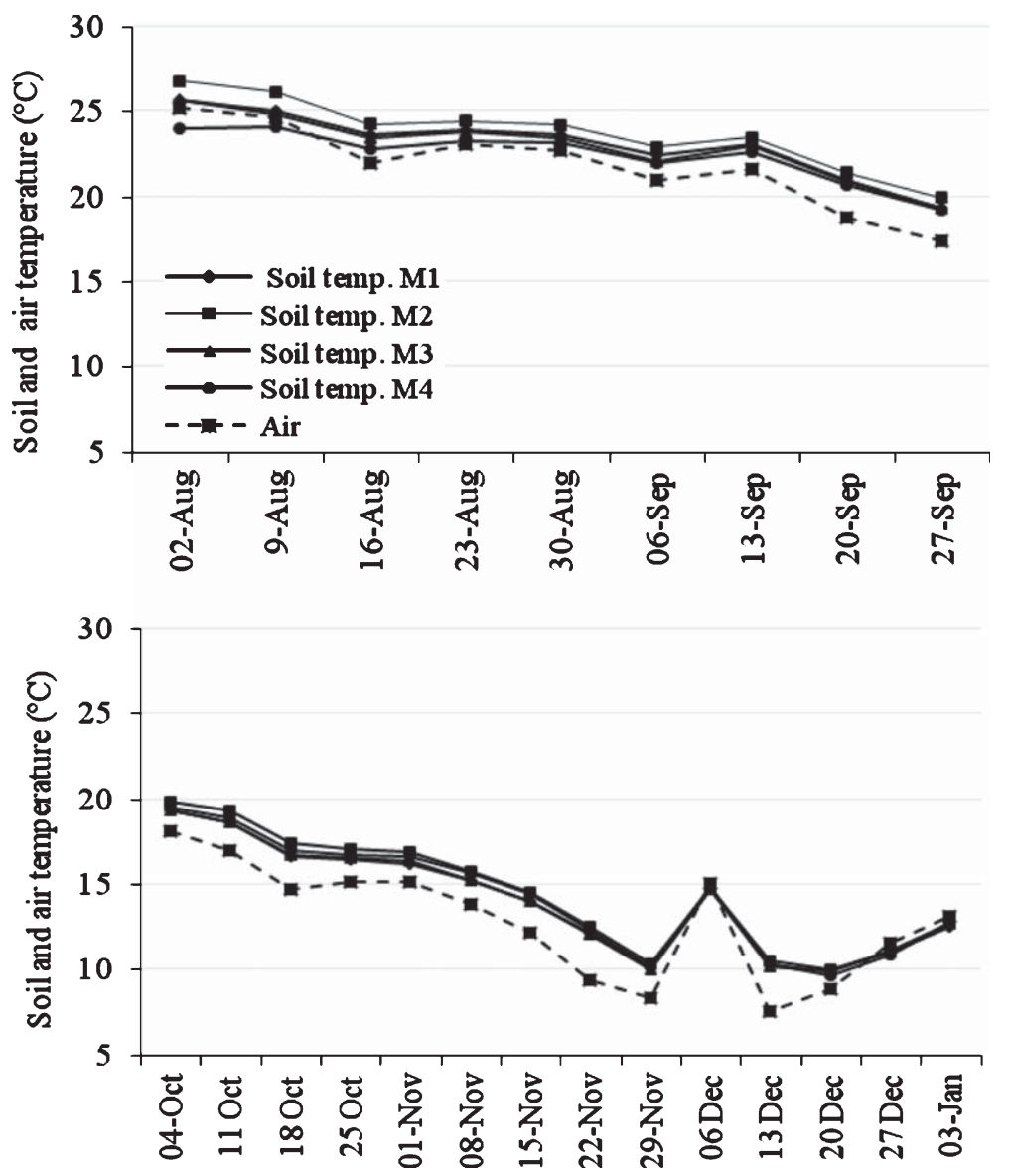

Fig. 1. Evolution of weekly soil and air mean temperatures during crop cycle in summer (a) and autumn-winter periods (b). M1 - Biomind, $31 \mu \mathrm{m}$ thick; M2 - Mater-Bi ${ }^{\circledR}, 20 \mu \mathrm{m}$ thick; M3 - Mater-Bi ${ }^{\circledR}, 25 \mu \mathrm{m}$ thick; M4 - PE, $40 \mu \mathrm{m}$ thick.

Table 3

Variation of weekly mean soil temperature $\left({ }^{\circ} \mathrm{C}\right)$ under biodegradable mulch treatments relative to PE mulch, during summer and autumn-winter periods

\begin{tabular}{|c|c|c|c|c|c|c|c|c|c|c|c|c|c|}
\hline & Summer period & & & & & & & & & & & & \\
\hline & 02Aug & 9Aug & 16Aug & 23Aug & 30Aug & 06Sep & 13Sep & 20Sep & $27 \mathrm{Sep}$ & & & & \\
\hline M1-M4 & 1.71 & 0.98 & 0.82 & 0.60 & 0.45 & 0.48 & 0.46 & 0.22 & 0.09 & & & & \\
\hline M2-M4 & 2.78 & 2.07 & 1.43 & 1.17 & 1.03 & 0.98 & 0.82 & 0.70 & 0.70 & & & & \\
\hline \multirow[t]{3}{*}{ M3-M4 } & 1.69 & 0.78 & 0.59 & 0.51 & 0.28 & 0.16 & 0.31 & 0.11 & 0.02 & & & & \\
\hline & Autumn-winter period & & & & & & & & & & & & \\
\hline & 04Oct & 11 Oct & 18 Oct & $25 \mathrm{Oct}$ & $01 \mathrm{Nov}$ & $08 \mathrm{Nov}$ & $15 \mathrm{Nov}$ & $22 \mathrm{Nov}$ & 29 Nov & 06Dec & 13Dec & 20Dec & 27Dec \\
\hline M1-M4 & -0.18 & -0.25 & -0.33 & -0.26 & -0.44 & -0.45 & -0.43 & -0.21 & -0.17 & -0.07 & -0.10 & 0.29 & 0.11 \\
\hline M2-M4 & 0.40 & 0.43 & 0.47 & 0.27 & 0.27 & 0.11 & 0.09 & 0.17 & 0.15 & 0.04 & 0.16 & 0.36 & 0.11 \\
\hline M3-M4 & -0.17 & -0.25 & -0.30 & -0.19 & -0.27 & -0.42 & -0.44 & -0.25 & -0.23 & 0.04 & -0.15 & 0.28 & 0.21 \\
\hline
\end{tabular}

M1 - Biomind, $31 \mu \mathrm{m}$ thick; M2 - Mater-Bi ${ }^{\circledR}, 20 \mu \mathrm{m}$ thick; M3 - Mater-Bi ${ }^{\circledR}, 25 \mu \mathrm{m}$ thick; M4 - PE, $40 \mu \mathrm{m}$ thick. 
Table 4

Monthly average values of the mean $\left(\mathrm{T}_{\text {mean }}\right)$, minimum $\left(\mathrm{T}_{\min }\right)$ and maximum $\left(\mathrm{T}_{\max }\right)$ air temperatures, relative humidity $(\mathrm{RH})$, water $(\mathrm{W})$ and solar radiation (SR) during the crop cycle

\begin{tabular}{|c|c|c|c|c|c|c|}
\hline & $\mathrm{T}_{\text {mean }}\left({ }^{\circ} \mathrm{C}\right)$ & $\mathrm{T}_{\min }\left({ }^{\circ} \mathrm{C}\right)$ & $\mathrm{T}_{\max }\left({ }^{\circ} \mathrm{C}\right)$ & RH (\%) & $\mathrm{W}(\mathrm{mm})$ & $\mathrm{SR}\left(\mathrm{W} \cdot \mathrm{m}^{-2}\right)$ \\
\hline July & 23.4 & 15.4 & 32.9 & 63.6 & $35.4^{*}$ & 5708 \\
\hline August & 23.6 & 15.7 & 33.0 & 65.7 & $96.8^{*}$ & 8434 \\
\hline September & 20.1 & 12.6 & 29.2 & 74.0 & $13.4^{*}$ & 6543 \\
\hline October & 16.4 & 10.5 & 26.0 & 83.0 & 6.2 & 3194 \\
\hline November & 12.3 & 7.3 & 20.4 & 87.0 & 4.2 & 2100 \\
\hline December & 10.4 & 6.3 & 16.4 & 90.6 & 74.2 & 1540 \\
\hline
\end{tabular}

* Rainfall and sprinkler water irrigation.

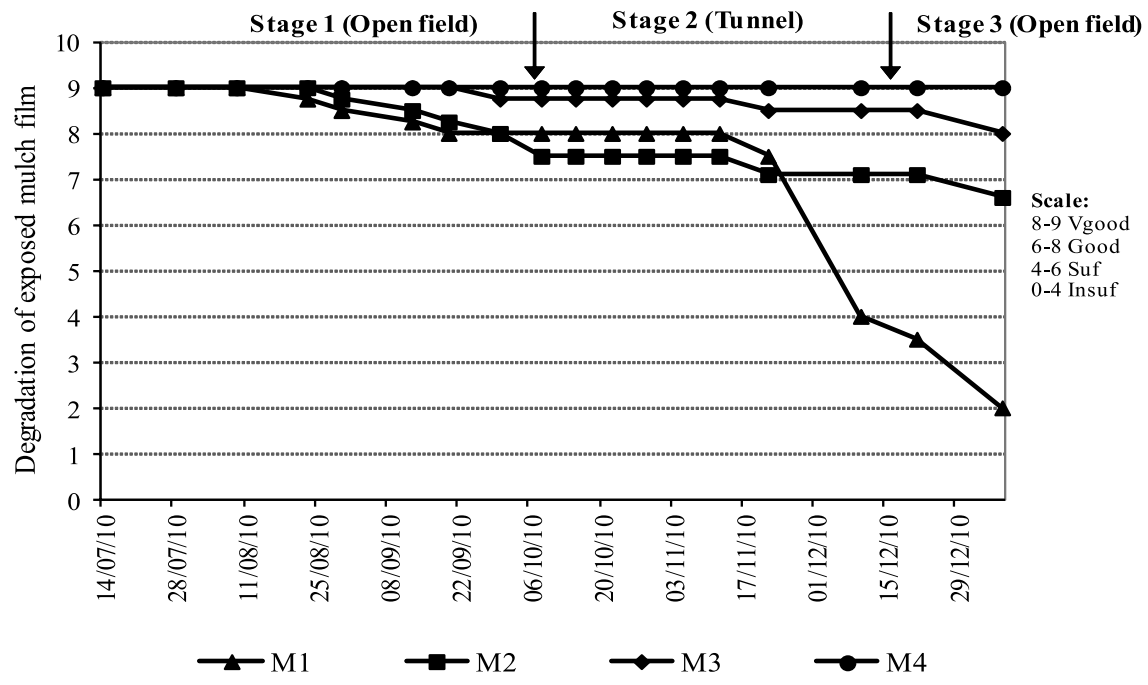

Fig. 2. Degradation of the exposed biodegradable mulches (M1 - Biomind, $31 \mu \mathrm{m}$ thick; M2 - Mater-Bi ${ }^{\circledR}, 20 \mu \mathrm{m}$ thick; $\mathrm{M} 3-\mathrm{Mater-Bi}{ }^{\circledR}, 25 \mu \mathrm{m}$ thick) and of conventional mulch (M4 - PE, $40 \mu \mathrm{m}$ thick) during open field (stages 1 and 3) and tunnel (stage 2).

BD mulching films [8]. However, in the middle of November the degradation process of M1 accelerated until the end of crop cycle. M1 was highly fragmented at the slightest touch, beginning to break into small pieces, with a texture similar to paper. This fact may be attributable to the composition of the M1 mulch film as M2 and M3 films only started to degrade after the removal of tunnel protection. The higher degradation of M2 was mainly due to its lower film thickness in comparison to M3. Although the occurrence of the BD mulch films degradation throughout the experiment, this did not impair the general appearance of the plants. In addition, they provided adequate weed suppression as illustrated in Fig. 3.

Concerning the degradation of the buried edges of the mulch films, M1 had a very rapid degradation during July and August while for M2 and M3 treatments this process was only observed in December (Fig. 4).

At the end of the crop cycle and before the incorporation of the biodegradable mulch films the final measurement of the mulch films degradation were performed and the mean values of degraded area per mulch treatment are presented in Table 5. The percentage of soil mulching surface with M1 was lower (20\%) compared with the M2 (70\%) and M3 $(86 \%)$ mulching surface. These measurements are in agreement with the final values of visual scale used.

The results obtained suggest that the different performance of M1 in relation to M2 and M3 films may be due to the composition of its material, although films thicknesses were different among them [16]. Between M2 and M3 mulch performance was influenced by films thickness, as they have the same composition and the differences were only in the exposed mulch. 



Fig. 3. Performance of mulch films at the end of crop season. a) M1 - Biomind, $31 \mu \mathrm{m}$ thick; b) M2 - Mater-Bi ${ }^{\circledR}, 20 \mu \mathrm{m}$ thick; c) M3 - Mater-Bi ${ }^{\circledR}$, $25 \mu \mathrm{m}$ thick; d) M4 - PE, $40 \mu \mathrm{m}$ thick.

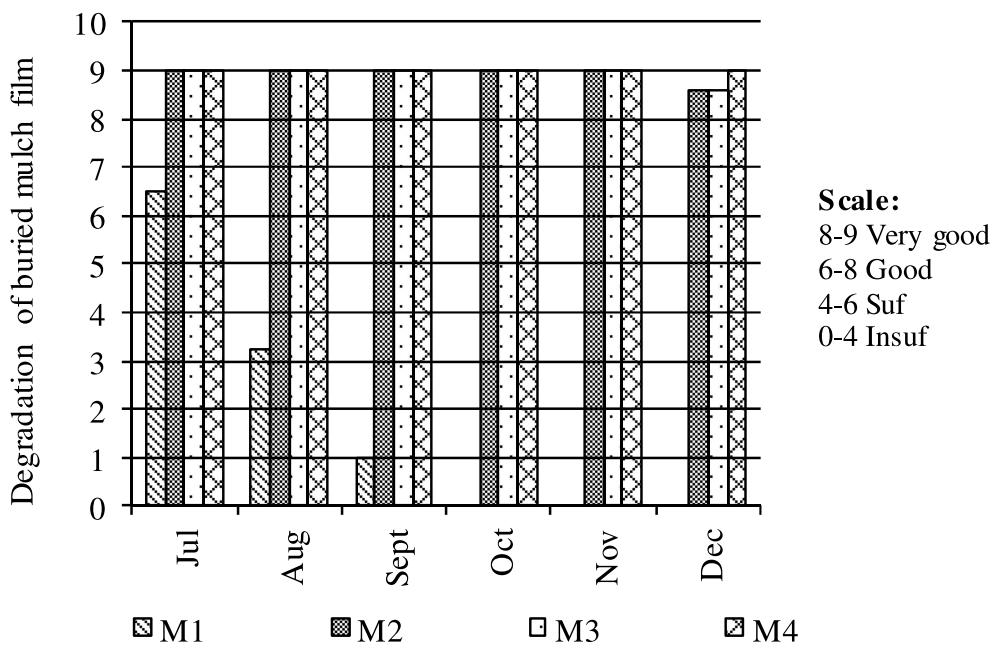

Fig. 4. Degradation of buried edges of biodegradable and of conventional mulch along the strawberry crop cycle. (M1 - Biomind, $31 \mu \mathrm{m}$ thick; M2 - Mater-Bi ${ }^{\circledR}, 20 \mu \mathrm{m}$ thick; M3 - Mater-Bi ${ }^{\circledR}, 25 \mu \mathrm{m}$ thick; M4 - PE, $40 \mu \mathrm{m}$ thick). 
Table 5

Mean degraded area ( \pm Standard Deviation) and initial and final covering area per mulch film treatment, before its incorporation into soil

\begin{tabular}{lcccc}
\hline & \multicolumn{3}{c}{ Treatment } \\
\cline { 2 - 5 } & M1 & M2 & M3 & M4 \\
\hline Initial covering area $\left(\mathrm{m}^{2}\right)$ & 10.4 & 10.4 & 10.4 & 10.4 \\
Mean degraded area $\left(\mathrm{m}^{2}\right)$ & $8.3 \pm 1.3$ & $3.2 \pm 1.2$ & $1.5 \pm 0.8$ & $0.0 \pm 0.0$ \\
Final covering area $(\%)$ & 20.4 & 70.1 & 85.9 & 100 \\
\hline
\end{tabular}

M1 - Biomind, $31 \mu \mathrm{m}$ thick; M2 - Mater-Bi ${ }^{\circledR}, 20 \mu \mathrm{m}$ thick; M3 - Mater-Bi ${ }^{\circledR}, 25 \mu \mathrm{m}$ thick; M4 - PE, $40 \mu \mathrm{m}$ thick.

Table 6

The effect of mulch film (M) on yield performance

\begin{tabular}{|c|c|c|c|c|c|c|c|}
\hline \multirow[t]{2}{*}{ Treatment } & \multirow{2}{*}{$\begin{array}{c}\text { Total yield } \\
\text { (g/plant) }\end{array}$} & \multicolumn{4}{|c|}{ Percent crop harvested per month } & \multirow{2}{*}{$\begin{array}{c}\mathrm{N}^{\circ} \\
\text { fruit/plant }\end{array}$} & \multirow{2}{*}{$\begin{array}{c}\text { Fruit } \\
\text { weight }(\mathrm{g})\end{array}$} \\
\hline & & Sept. & Oct. & Nov. & Dec. & & \\
\hline M1 & $317.7 \mathrm{~b}$ & $12.7 \mathrm{a}$ & $55.8 \mathrm{a}$ & $25.9 \mathrm{a}$ & $5.6 \mathrm{a}$ & $24.6 \mathrm{~b}$ & $13.7 \mathrm{a}$ \\
\hline M2 & $390.8 \mathrm{~b}$ & $10.5 \mathrm{a}$ & $51.7 \mathrm{a}$ & $28.4 \mathrm{a}$ & $9.5 \mathrm{a}$ & $29.8 \mathrm{~b}$ & $13.7 \mathrm{a}$ \\
\hline M3 & $415.4 \mathrm{~b}$ & $12.1 \mathrm{a}$ & $54.4 \mathrm{a}$ & $25.1 \mathrm{a}$ & $8.4 \mathrm{a}$ & $31.6 \mathrm{~b}$ & $13.8 \mathrm{a}$ \\
\hline M4 & $508.7 \mathrm{a}$ & $12.9 \mathrm{a}$ & $53.9 \mathrm{a}$ & $25.3 \mathrm{a}$ & $7.8 \mathrm{a}$ & $40.1 \mathrm{a}$ & $13.3 \mathrm{a}$ \\
\hline
\end{tabular}

M1 - Biomind, $31 \mu \mathrm{m}$ thick; M2 - Mater-Bi ${ }^{\circledR}, 20 \mu \mathrm{m}$ thick; M3 - Mater-Bi ${ }^{\circledR}, 25 \mu \mathrm{m}$ thick; M4 - PE, $40 \mu \mathrm{m}$ thick. Values within column followed by the same letter are not significantly different at $P \leq 0.05$.

\subsection{Fruit yield}

Yields for all biodegradable mulch films were significantly lower than for PE mulch film (Table 6). The mean loss of crop yield was about 20\% for M2 and M3 and 37\% for M1 compared to PE mulch film (M4). No significant differences were observed on fruit yield among biodegradable mulch films. The highest fruit production occurred during October and November.

The highest yield on M4 may be related to the lowest soil temperature of this plot, mainly during the beginning of the trial (July and August), when the air temperature was very high. With these high temperatures, plant growth and development may have been favored by a soil temperature more adequate to their development [19], leading to a better crop yield.

Despite the differences in the total yield among mulch treatments, no significant differences were found in the percentage of commercial and uncommercial fruits, which was about $82 \%$ and $18 \%$ respectively. Mulch treatment had no effect on fruit production per month.

The number of fruits was significantly higher on $\mathrm{M} 4$ than in the biodegradable mulch films plots with no differences among the last ones (Table 6). The highest number of fruits on M4 led to highest fruit yield as average fruit weight was not affected by mulch treatment. These findings agree with Himelrick [20].

\subsection{Cost analysis}

Costs of BD and PE films, including product, removal and disposal costs are presented in Table 7. The use of BD films increases the amount of input costs for the strawberry grower because of its high price which is practically three times the PE cost.

The costs of removing and of the transport for disposal of the conventional polyethylene much film was nearly nine times more expensive than the costs of burying the biodegradable mulch films together with the crop residues into the soil (Table 7). These high costs are mainly due to human labor and machinery which totalized $106 \mathrm{~h} / \mathrm{ha}$ for 
Table 7

Comparison between the costs of $\mathrm{BD}$ and $\mathrm{PE}$ mulch films per hectare for autumn-winter strawberry production

\begin{tabular}{lcccc}
\hline Variables & \multicolumn{2}{c}{ Biodegradable mulch film } & PE mulch \\
\cline { 2 - 4 } & M1 & M2 & M3 & M4 \\
\hline Plastic cost (€/kg) & 5.85 & 6.25 & 6.25 & 1.95 \\
Quantity of plastic (kg/ha) & 510 & 305 & 382 & 438 \\
Plastic cost (€/ha) & 2984 & 1906 & 2388 & 854 \\
Average incorporation cost (€/ha) & 60 & 60 & 60 & 0 \\
Average removal and disposal costs (€/ha) & 0 & 0 & 0 & 548 \\
Overall costs (€/ha) & 3044 & 1966 & 2448 & 1402 \\
Overall cost difference (\%) (base: PE) & 117.1 & 40.2 & 74.6 & - \\
Government incentive for BD plastic (\%) & 31.3 & 31.3 & 31.3 & 0 \\
Plastic cost with incentive (€/ha) & 2050 & 1310 & 1640 & 1402 \\
Overall cost with incentive & 2110 & 1370 & 1700 & 1402 \\
Overall cost difference with incentive (\%) (base:PE) & 50.5 & -2.3 & 21.3 & - \\
\hline
\end{tabular}

M1 - Biomind, $31 \mu \mathrm{m}$ thick; M2 - Mater-Bi ${ }^{\circledR}, 20 \mu \mathrm{m}$ thick; M3 - Mater-Bi ${ }^{\circledR}, 25 \mu \mathrm{m}$ thick; M4 - PE, $40 \mu \mathrm{m}$ thick.

polyethylene mulch removal and transport operations in contrast to $4 \mathrm{~h} / \mathrm{ha}$ for biodegradable mulch film incorporation in the soil.

Comparing the total costs of using these two types of plastic mulch it is clearly evident that using BD mulch films remains expensive due to its high prices, which has been already reported [21]. However, in order to accomplish sustainable agriculture practices, Portuguese government gives financial support for the application of these kinds of mulches. Applying this incentive the use of BD mulch represented a less investment for the farmers.

\section{Conclusions}

The purpose of this study was to evaluate the performance of white-on-black biodegradable (BD) mulch films in autumn-winter cycle strawberry production and its effects on soil heating and plant productivity. Soil temperature and mulch films performance were affected by film thickness and material composition.

Biodegradable mulch films M2 and M3 (made from Mater-Bi ${ }^{\circledR}$ raw material) underwent to a lower degradation showing $78 \%$ of soil coverage at the end of the crop cycle in contrast to M1 BD mulch film (Biomind raw material) that had $20 \%$ of soil coverage. This last one also had a fast degradation of the buried edges. Although these changes in the film structure BD mulch films provided adequate bedcover during the growing season over five months.

The differences in soil temperature between BD and polyethylene (PE) mulch films were more evident in the summer period. The BD mulches warmed soils more than PE mulch during summer which might have contributed to less number of fruits produced and consequently to lower plant productivity.

From the overall results obtained, the use of biodegradable plastic materials for mulching may be a promising alternative to PE mulching due to their progressive degradation throughout the growing season and because they provided an adequate ground cover and an efficient control of weeds as well as retaining fruits free from the soil. However there should be governmental economic incentives in order to implement this practical as the plastic cost remains still too expensive.

\section{Acknowledgments}

This research was supported by funding from OP Lusomorango and European Research Project FP7-SME-2010 "Development of enhanced biodegradable films for agricultural activities-AGROBIOFILM". 


\section{References}

[1] Lalitha M, Kasthuri Thilagam V, Balakrishnan N, Mansour M. Effect of plastic mulch on soil properties and crop growth - a review. Agric Rev. 2010;31:145-9.

[2] Lamont WJ. Plastics: Modifying the microclimate for the production of vegetable crops. HortTechnology. 2005;15:477-81.

[3] Hayes D, Dharmalingam S, Wadsworth LC, Leonas KK, Miles C, Inglis D. Biodegradable agricultural mulches derived from biopolymers. In: Khemani KC, Scholz C, editors. Degradable Polymers and Materials: Principles and Practice. Washington, DC: American Chemical Society, 2012, pp. 201-223.

[4] Kyrikou I, Briassoulis D. Biodegradation of agricultural plastic films: A critical review. J Polym Environ. 2007;15:125-50.

[5] Briassoulis D, Dejean C. Critical review of norms and standards for biodegradable agricultural plastics. Part I. Biodegradation in soil. J Polym Environ. 2010;18:384-400.

[6] Kasirajan S, Ngouajio M. Polyethylene and biodegradable mulches for agricultural applications: A review. Agron Sustain Dev. 2012;32:50129.

[7] Martín-Closas L, Pelacho AM. Agronomic potential of biopolymer films. In: Plackett D. editor. Biopolymers - New materials for sustainable films and coatings. UK, John Wiley \& Sons Ltd, Chichester, 2011.

[8] Briassoulis D. Analysis of the mechanical and degradation performances of optimised agricultural biodegradable films. Polym Degrad Stabil. 2007;921:1115-32.

[9] Kapanen A, Schettini E, Vox G, Itavara M. Performance and environmental impact of biodegradable films in agriculture: A field study on protected cultivation. J Polym Environ. 2008;16:109-122.

[10] Saraiva A, Costa R, Carvalho L, Duarte E. The use of biodegradable mulch films in muskmelon crop production. Basic Research Journal of Agricultural Science and Review. 2012;1:88-95. (http//www.basicresearchjournals.org)

[11] Costa R, Saraiva A, Carvalho L, Duarte E. The use of biodegradable mulch films on strawberry crop in Portugal. Scientia Horticulturae 2014;173:65-70.

[12] Palha MG. Strawberry growth and development in the mild winter European regions. International Journal of Fruit Science. 2005;5(1):83-90.

[13] OMAIAA. www.observatorioagricola.pt/

[14] Briassoulis D, Hiskakis M, Babou E. Technical specifications for mechanical recycling of agricultural plastic waste. Waste Management. 2013;33:1516-30.

[15] Miles C, Klingler E, Nelson L, Smith T, Cross C. Alternatives to plastic mulch in vegetables production systems. WSU Vancouver Research \& Extension Unit, Annual Report. 2007;17. http://vegetables.wsu.edu/MulchReport07.pdf

[16] Vox G, Schettini E. Evaluation of the radiometric properties of starch-based biodegradable films for crop protection. Polym Test. 2007;26:639-51.

[17] Bilck AP, Grossmann MVE, Yamashita F. Biodegradable mulch films for strawberry production. Polym Test. 2010;29:471-6.

[18] Moreno MM, Moreno A. Effect of different biodegradable and polyethylene mulches on soil properties and production in a tomato crop. Sci Hortic. 2008;116:256-63.

[19] Palha MG. A planta do morangueiro. In: Palha MG, editor. Manual do morangueiro. Oeiras, INIAP/EAN, 2005, p. 128. (ISBN 972-579-00-8)

[20] Himelrick DG. Effect of polyethylene mulch colour on soil temperatures and strawberry plant responses. Adv. Strawberry Prod. 1982;1: 15-6.

[21] Cirujeda A, Aibar J, Anzalone A, Martin-Closas L, Meco R, Moreno, MM, Pardo, A, Pelacho AM, Rojo F, Royo-Esnal A, Suso ML, Zaragoza C. Biodegradable mulch instead of polyethylene for weed control f processing tomato production. Agron Sustain Dev. 2012;32: 889-97. 